\title{
Interaction between Starch and Fatty Acid Esters in Frozen Starch Noodles
}

\author{
Zen-ichi MOHRI \\ Wakayama Research Laboratories, Kao Soap Co., Ltd., Wakayama-shi, Japan \\ Received April 9, 1979
}

\begin{abstract}
The mechanism of the separating effect of fatty acid ester (FAE) has been studied in frozen starch noodles (FSN). This was examined by FAE adsorption on the starch surface and by FAE effects on viscosity, adhesive force, syneresis and iodine-affinity of starch paste. The present and previous results indicate that separating effect of FAE has a close relationship to the interaction of FAE with starch. The following factors are at least important in the separating effect of FAE; (a) adsorption of FAE on starch surface and (b) the subsequent action of FAE to reduce the viscosity and adhesive force of starch paste. The reason for FAE, especially sorbitan stearate or glycerin stearate, being effective in the separating action of FSN probably lies in the FAE ability to satisfy the above requirements.
\end{abstract}

A previous work ${ }^{1 /}$ showed that fatty acid ester (abbreviated as FAE) had a facilitating effect on the separation of frozen starch noodle (abbreviated as FSN). The separating effect of FAE increased in proportion to the length of the alkyl chain of FAE. Further, the separating effect was found to be closely related to the HLB (Hydrophilic Lypophilic Balance)')value of FAE.

Many research workers have investigated the interaction of starch with various reagents, especially nonionic surfactants such as glycerin fatty acid ester. However, many of their works related to the staling process of bread.

FSN is manufactured as follows: After a mixture of sweet potato and potato starches is pushed out of a nozzle and gelatinized, the noodle obtained is frozen overnight at $-10^{\circ} \mathrm{C}$ and thawed to facilitate the subsequent separation of noodles. With respect to the manufacturing process of FSN, the separating effect of FSN by FAE is thought to have a close relationship with the interaction of FAE with starches as starting materials. However, no such investigations have been reported yet. In the present work, the relation between the separating effect of FAE on FSN and the interaction of FAE with starches has been studied to verify the above-mentioned conception in connection with complex-formation, syneresis, iodineaffinity, viscosity and adhesive force of starch in the presence of FAE and also the adsorption of FAE on starch surfaces.

\section{MATERIALS AND METHODS}

Materials. Potato and sweet potato starches were obtained from Wako Pure Chemical Ind. Ltd.; amylose was from Katayama Chemical Co., and FAE was prepared by the conventional method. Other chemicals were of the highest purity commercially available.

Determination of FAE adsorbed on starch. Mixtures of $\operatorname{starch}(3 \mathrm{~g})$, FAE $(0.2 \mathrm{~g})$ and distilled water $(200 \mathrm{ml})$ were stirred at $40^{\circ} \mathrm{C}$ for $4 \mathrm{hr}$. After cooling to room temperature, excess FAE was extracted twice with $100 \mathrm{ml}$ of chloroform and thoroughly dehydrated with sodium sulfate anhydrous. After evaporation and subsequent weighing, the amount of FAE which had adsorbed on starch was calculated from the results of the evaporated residue.

Determination of syneresis of starch gel. One hundred grams of suspension containing $0.5 \%$ FAE and $6 \%$ starch was vigorously stirred in a boiling water bath for $12 \mathrm{~min}$. The reaction mixtures (gels) were let stand for 3 or 6 days in a refrigerator. After standing, the gels were finely crushed and filtered through No. $5 \mathrm{~A}$ filter paper for $4 \mathrm{hr}$ to separate water liberated from the gels.

Determination of viscosity of starch paste. A suspension containing $0.5 \%$ FAE and $5 \%$ starch was stirred in a boiling water bath for $5 \mathrm{~min}$. After cooling to room temperature, the starch paste viscosity was determined with a Brookfield viscometer at $25^{\circ} \mathrm{C}$. 
Measurement of adsorption spectra of iodine starch complex. A paste containing 3\% starch and $0.03 \%$ FAE was stirred at $80^{\circ} \mathrm{C}$ for $4 \mathrm{hr}$. Five mililiters of the suspension and $1 \mathrm{ml}$ of $0.1 \%$ iodine solution were poured into a $100 \mathrm{ml}$ measuring flask, which was filled up to $100 \mathrm{ml}$ with distilled water. The flask was stoppered and allowed to stand overnight at room temperature, and then the absorbance of the mixture was measured at $610 \mathrm{~nm}$ on a spectrophotometer (Shimadzu Spectrometer 20) with $1-\mathrm{cm}$ cells.

Determination of adhesive force of starch. Starch paste was prepared by cooking $5 \%$ starch at $90^{\circ} \mathrm{C}$ for $5 \mathrm{~min}$. A $0.02 \mathrm{ml}$ portion of the paste was spread over a circular spot (diameter $4 \mathrm{~mm}$ ) at the end of a kraft paper piece $(15 \times 60 \mathrm{~mm})$, and then $0.05 \mathrm{ml}$ of the solution containing $0.15 \%$ sucrose oleate and $0.15 \%$ other FAE was dropped on the spot of starch. Another piece of Kraft paper of the same size was superimposed, and the end of the kraft paper was pasted over the above-mentioned circular spot of starch on which a hundred-gram weight was loaded for $5 \mathrm{~min}$. After the weight was removed, the pasted portion was allowed to stand for $2 \mathrm{hr}$ at $-10^{\circ} \mathrm{C}$. The tensile force required to separate the thin film of starch between the kraft paper pieces was measured by the use of Tensilon UTM-III (Toyo Measuring Instruments Co. Tokyo).

\section{RESULTS AND DISCUSSION}

\section{Influence on adsorption of FAE on starch}

Table I shows the results of the experiments in an aqueous medium in which the adsorptivity of FAE on starches has been investigated. It was found that the amounts of FAE adsorbed on starch were highly dependent on the molecular weights of FAE-the greater the adsorption amount of FAE, the longer the alkyl chain length of FAE. These results agreed with those described by Lagendijk and Pennings. ${ }^{3)}$ Further, as the degree of esterification increases, the adsorption ability of glycerin fatty acid ester decreases. Because of the steric hindrance, the trioleate will not easily adsorb on starch surface. These results indicate the order of the adsorptivity to be in accord with that of the separating effect of FAE on FSN reported in a preceding paper. ${ }^{1}$ )

Therefore, a correlation was found between the adsorptivity and the separating effect of FAE.
Table I. Determination of Fatty Act Ester Content Adsorbed on Starch

\begin{tabular}{ccc}
\hline Starch & $\begin{array}{c}\text { Sorbitan and } \\
\text { glycerin fatty } \\
\text { acid ester }\end{array}$ & $\begin{array}{c}\text { Amount of } \\
\text { fatty acid } \\
\text { ester adsorbed } \\
\text { mmol/g starch } \cdot 10^{5}\end{array}$ \\
\hline Potato & Glycerin & \\
& Monolaurate & 42.3 \\
& Monopalmitate & 82.1 \\
& Monostearate & 137.9 \\
& Monooleate & 96.0 \\
& Dioleate & 96.0 \\
Dweet & Dioleate & 62.1 \\
potato & Grioleate & 30.3 \\
\hline & Monolaurate & 55.2 \\
& Monopalmitate & 64.6 \\
\hline Potato & Monostearate & 78.4 \\
\hline & Sorbitan & 133.8 \\
& Monolaurate & 154.3 \\
& Monopalmitate & 180.0 \\
& Monostearate & 157.5 \\
\hline
\end{tabular}

These values are the averages of three tests.

\section{Influence of complex formation of iodine-starch} by $F A E$

As shown in Table II, all the FAE employed in this investigation greatly reduced the absorbance of complex, namely, iodine-affinity of starch.

The iodine-affinity of starch decreased with the increase of alkyl chain in FAE. As compared with sorbitan ester, glycerin ester was

Table II, IInfluence of Fatty Acid Ester on AbSORPtion OF IODINE STARch COMPLEX

\begin{tabular}{|c|c|c|c|}
\hline \multirow{2}{*}{\multicolumn{2}{|c|}{$\begin{array}{l}\text { Fatty acid ester } \\
\text { (FAE) }\end{array}$}} & \multicolumn{2}{|c|}{$\begin{array}{l}\text { Decreasing ratio } \\
\text { Rate of absorption } \\
(\%) \text { at } 610 \mathrm{~nm}\end{array}$} \\
\hline & & Potato & Sweet potato \\
\hline \multirow[t]{3}{*}{ Sorbitan } & monolaurate & 56.4 & 90.5 \\
\hline & monooleate & 47.6 & 50.0 \\
\hline & monostearate & 16.6 & 29.3 \\
\hline \multirow[t]{3}{*}{ Glycerin } & monolaurate & 45.5 & 92.0 \\
\hline & monooleate & 32.1 & 48.0 \\
\hline & monostearate & 11.8 & 26.7 \\
\hline
\end{tabular}

Fatty acid ester/starch $=1 / 100$.

These values are the averages of three tests.

a Ratio is expressed in

OD* without FAE-OD in the presence of FAE $\times 100$. OD without FAE

* $\mathrm{OD}=$ Optical density. 
less effective in lowering the iodine-affinity. The iodine-affinity of potato starch was higher than that of sweet potato starch. The molecular weight of FAE was found to be closely related to its ability to suppress iodine color development as described in Maesawa's report ${ }^{4}$-the higher the molecular weight, the smaller the lowering ability. As the molecular weight decreases, FAE seems to penetrate easily into the amylose helix and lowers the iodine color development to form a complex with starch. From the result obtained here, the order of the separating effect of FAE on FSN did not agree with that of the decreasing effect of FAE on the iodine-affinity of starch. In the range of this experiment, no clear relationship was found between the separating effect of FAE and its decreasing effect on the iodine-affinity of starch.

\section{Influence of FAE on syneresis of starch gel}

As shown in Table III, all the FAE employed in this investigation promoted syneresis. Especially, as the water-solubility of FAE, namely, HLB-value increased, the starch gel containing FAE showed remarkable syneresis. According

TABle III. INFLUENCE OF FATTY ACID Ester ON SYNERESIS OF $6 \%$ STARCH GEL

\begin{tabular}{|c|c|c|c|c|}
\hline \multirow{3}{*}{$\begin{array}{l}0.5 \% \\
\text { Fatty acid ester }\end{array}$} & \multicolumn{4}{|c|}{ Syneresis ratio $(\%)$} \\
\hline & \multicolumn{2}{|c|}{3 rd day } & \multicolumn{2}{|c|}{6 th day } \\
\hline & $P$ & $S$ & $\mathbf{P}$ & $S$ \\
\hline No addition & 0 & 5.29 & 0.39 & 18.67 \\
\hline \multirow{4}{*}{$\begin{array}{l}\text { Glyecein monolaurate } \\
\text { monopalmitate } \\
\text { monooleate } \\
\text { monostearate }\end{array}$} & 1.82 & 17.19 & 2.54 & 28.00 \\
\hline & 1.06 & 10.61 & 1.23 & 20.35 \\
\hline & 1.23 & 15.67 & 1.98 & 22.41 \\
\hline & 0.71 & 8.02 & 1.09 & 20.83 \\
\hline \multirow{4}{*}{$\begin{array}{l}\text { Sorbitan monolaurate } \\
\text { monopalmitate } \\
\text { monooleate } \\
\text { monostearate }\end{array}$} & 2.50 & 15.71 & 5.19 & 33.94 \\
\hline & 0.14 & 6.88 & 0.81 & 22.73 \\
\hline & 1.05 & 12.56 & 2.86 & 30.74 \\
\hline & 0.11 & 6.28 & 0.39 & 19.55 \\
\hline \multirow{4}{*}{$\begin{array}{ll}\text { Sucrose } & \text { monolaurate } \\
& \text { monopalmitate } \\
\text { monooleate } \\
\text { monostearate }\end{array}$} & 4.10 & 38.21 & 4.68 & 39.04 \\
\hline & 1.27 & 27.88 & 1.62 & 33.53 \\
\hline & 3.74 & 36.95 & 3.77 & 38.33 \\
\hline & 1.20 & 24.78 & 1.52 & 30.95 \\
\hline
\end{tabular}

Note: $P$, potato; $S$, sweet potato.

a Ratio is expressed in

Water content separated from sample gels $\times 100$. Water content in sample gels

These values are the averages of three tests. to Kimura, Watanabe and Ishizuka, ${ }^{5)}$ it seems that the syneresis is caused by the decrease of hydration power of starch owing to the occurrence of a strong hydrogen bond between FAE and starch. Maesawa and Ohkubo ${ }^{4}$ reported that the syneresis of sweet potato starch gel was greater than that of potato starch gel. In this investigation, similar results were obtained.

From the result presented here, the order of the separating effect of FAE on FSN did not agree with that of the accelerating effect of FAE on the syneresis of starch gel. In the range of this experiment, no remarkable relationship between the separating effect and syneresis accelerating effect of FAE was observed like in the case of iodine-affinity.

\section{Influence of FAE on viscosity of starch paste}

Table IV shows the influence of FAE on the viscosity of starch paste.

All the FAE employed in this investigation were effective in lowering the viscosity of starch paste. However, contrary to the results regarding the syneresis mentioned already, the viscosity of starch paste decreased with the decrease in water-solubility of FAE, in other words-the higher the HLB of FAE,

TABLE IV. INFLUENCE OF FATty ACid Ester ON Viscosity of $5 \%$ STARCH PASTE

\begin{tabular}{ccr}
\hline Starch & $0.5 \%$ Fatty acid ester & Viscosity ${ }^{a}(\mathrm{cp})$ \\
\hline Potato & Glycerin monolaurate & 8,517 \\
& monooleate & 6,667 \\
& monostearate & 2,900 \\
& Sorbitan monolaurate & 12,400 \\
& monooleate & 8,783 \\
& monostearate & 6,567 \\
Sweet & Glycerin monolaurate & $>50,000$ \\
potato & monooleate & 10,717 \\
& monostearate & 8,117 \\
& Sorbitan monolaurate & 3,167 \\
& monooleate & 14,717 \\
& Control & 13,133 \\
& monostearate & 8,483 \\
& & $>50,000$ \\
\hline
\end{tabular}

a Viscosity was determined with a Brookfield viscometer at room temperature after gelatinization.

These values are the averages of three tests. 
the higher the viscosity of starch paste containing them.

Generally, the starch paste containing glycerin fatty acid eater showed a lower viscosity than that containing sorbitan fatty acid eater. Glycerin monostearate gave the lowest viscosity among these FAE.

From the results shown here, the order of the separating effect of FAE on FSN agreed with that of the decreasing effect of FAE on starch paste viscosity. The separating effect of FAE seems to be closely related to their effect to decrease the viscosity of starch paste.

\section{Influence of $F A E$ on adhesive force of starch}

Table V shows the influence of FAE on the adhesive force of starch. All the FAE employed in this investigation were effective in decreasing the adhesive force of starch. The adhesive force decreasing effect of FAE heavily depends on the molecular weight of FAE and, in general, increases with the molecular weight. Further, the effect of FAE to reduce the adhesive force of starch was shown to be closely related to their ability to separate FSN. The order of the adhesive force decreasing effect of FAE also agreed with that of the separating

Table V. Influence of Fatty Acid Ester on AdHesive Force ${ }^{a}$ of STARCH

\begin{tabular}{|c|c|c|c|c|}
\hline \multicolumn{2}{|c|}{ Fatty acid ester } & \multicolumn{3}{|c|}{$\begin{array}{c}\text { Adhesion Force } \\
\qquad\left(\mathrm{kg} / \mathrm{cm}^{2}\right)\end{array}$} \\
\hline & & $\mathrm{S} / \mathrm{P}=1 / 9$ & $5 / 5$ & $9 / 1$ \\
\hline \multicolumn{2}{|c|}{ No addition } & 482 & 411 & 360 \\
\hline \multirow[t]{3}{*}{ Glycerin } & monocaprylate & 400 & 368 & 340 \\
\hline & monolaurate & 362 & 330 & 298 \\
\hline & monostearate & 293 & 230 & 219 \\
\hline \multirow[t]{3}{*}{ Sorbitan } & monolaurate & 325 & 315 & 303 \\
\hline & monooleate & 312 & 282 & 253 \\
\hline & monostearate & 302 & 257 & 218 \\
\hline \multirow[t]{3}{*}{ Sucrose } & monolaurate & 409 & 364 & 330 \\
\hline & monooleate & 384 & 359 & 319 \\
\hline & monostearate & 343 & 337 & 295 \\
\hline
\end{tabular}

Note: $S$, sweet potato; $P$, potato.

a Adhesive force is expressed in terms of tensile strength after standing at $-10^{\circ} \mathrm{C}, 2 \mathrm{hr}$.

$b$ These fatty acid esters were tested in watersoluble emulsion by the use of an equal portion of sucrose oleate. Total concentration $=0.3 \%$.

c These values are the averages of three tests. effect of FAE on FSN.

As compared with sucrose fatty acid ester, glycerin and sorbitan fatty acid esters were relatively effective in decreasing the adhesive force of starch. The mixing ratio of sweet potato and potato starches influenced the adhesive force decreasing effect of FAE. As the proportion of potato starch increases, this effect of FAE weakens gradually, and conversely, the adhesive force of starch decreases in proportion to the increasing content of sweet potato starch.

The adhesive force of potato starch was shown to be greater than that of sweet potato starch. This result agreed with that described by Takahashi. ${ }^{6)}$

On the other hand, potato starch was more difficult than sweet potato in the separation of FSN as reported in the preceding paper." Therefore, as proposed by Yamamura, ${ }^{71}$ these results prove that the adhesive force of starch is closely related to the separation of FSN.

Furthermore, it was verified that one of the main effects of FAE related to the separation of FSN was due to the decreasing effect on the adhesive force of starch used as starting material.

As shown in Table VI, only a small difference was found between the standing conditions affecting the adhesive force of starch. Table VII shows the relation between the adhesive force of starch and the concentration of separating agent reported in the preceding paper. ${ }^{11}$

The concentration of separating agent was found to be heavily dependent on the adhesive force. The adhesive force of starch decreased with the increasing concentration of separating agent. In fact, this experimental data showed that weakening the adhesive force of starch

Table VI. Influence of Standing Condition on AdHesive ForCe of STARCH ${ }^{a}$

\begin{tabular}{cc}
$\begin{array}{c}\text { Standing } \\
\text { Condition }\end{array}$ & $\begin{array}{c}\text { Adhesive force } \\
\left(\mathrm{kg} / \mathrm{cm}^{3}\right)\end{array}$ \\
\hline$-10^{\circ} \mathrm{C}, 2 \mathrm{hr}$ & 332 \\
$20^{\circ} \mathrm{C}, 2 \mathrm{hr}$ & 307 \\
\hline
\end{tabular}

Sweet potato/Potato $=1 / 9$.

$b$ These values are the averages of three tests. 
TABle VII. Influence of Concentration of Separating Agent ${ }^{a}$ on Adhesive ForCE OF STARCH ${ }^{b}$

\begin{tabular}{llc}
\hline \multicolumn{1}{c}{$\begin{array}{c}\text { Separating agent } \\
(\%)\end{array}$} & $\begin{array}{c}\text { Adhesive force } \\
\left(\mathrm{kg} / \mathrm{cm}^{2}\right)\end{array}$ \\
\hline 0 & 284 \\
& 201 \\
& 1.0 & 152 \\
\hline$a$ & Composition of separating agent: Sorbitan \\
& monostearate, $50 \%$; Sucrose monooleate, $50 \%$. \\
b & Sweet Potato/Potato=1/9. \\
C Same as in Table V.
\end{tabular}

These values are the averages of three tests.

disturbing the separation of FSN was an important factor to promote the separation of FSN. From the above discussion, whatever the detailed mechanism may be, in the region of this experiment, we can understand that FAE have an effect on the separation of FSN, which would be attributable to the adsorption of FAE on the surface of the starch and the lowering of viscosity and adhesive force of starch paste as starting materials of FSN rather than the complex formation such as the syneresis and the lowering of iodine-affinity of starch.
Especially, the adsorption of FAE on starch seems to act as a rate-limiting step; namely, the greater the adsorption amount of FAE on starch, the stronger its viscosity- and adhesiondecreasing effect on starch and its subsequent facilitating effect on FSN separation. This could be explained by the fact that a close correlation was observed among these orders of effects.

\section{REFERENCES}

1) Z. Mohri and J. Tamura, J. Nutr. Sci. \& Vitaminol. 32, 223 (1979).

2) W. C. Griffin, F. Soc. Cosmetic Chemist's, 1, 311 (1949).

3) J. Lagendijk and H.J. Pennings, Cereal Sci. Today, 10, 354 (1970).

4) T. Maesawa and M. Ohkubo, J. Jpn. Soc. Starch Sci., 10, 111 (1963).

5) Y. Kimura, T. Watanabe and T. Ishizuka, Nippon Shokuhin Kogyogakkaishi, 18, 333 (1971).

6) R. Takahashi, J. Jpn. Soc. Starch Sci., 21, 59 (1974).

7) E. Yamamura, T. Kono, N. Okamoto and K. Honbo, Kagoshimaken Nogyoshikenjyohokoku, 1967,46 . 